\title{
A Novel FECH Mutation Causes Erythropoietic Protoporphyria with Severe Liver Dysfunction
}

\author{
Fang $\mathrm{Xu}^{1}$, Xiaomei Wang ${ }^{1}$, Xiumei $\mathrm{Chi}^{1}{ }^{1}$, Xiuting $\mathrm{He}^{1}$, Yue $\mathrm{Qi}^{1}{ }^{1}$, Huijuan Peng ${ }^{1}$, Junqi Niu ${ }^{1}$, Yanjun Cai ${ }^{1}{ }^{\text {, }}$ \\ and Pujun Gao ${ }^{1, * *}$ \\ ${ }^{1}$ The First Hospital of Jilin University, Changchun, China \\ "Corresponding author: The First Hospital of Jilin University, Changchun, China. Tel: + 86-43188782437, Email: caiyanjun126@126.com \\ "Corresponding author: Department of Hepatology, The First Hospital of Jilin University, Changchun, China. Email: pujungao@126.com \\ Received 2018 June 13; Revised 2018 August 08; Accepted 2018 September 14
}

\begin{abstract}
Background: Erythropoietic protoporphyria (EPP) is a rare autosomal dominant disease that is caused by partial ferrochelatase (FECH) deficiency because of a genetic mutation in the $F E C H$ gene.

Objectives: The aim of this study was to investigate the genetic mechanism of EPP in a Chinese family.

Methods: Clinical physical examination, laboratory testing, and medical history tracking were performed for phenotyping. The $F E C H$ gene was sequenced for genotyping.

Results: The proband presented EPP with severe liver dysfunction. A novel nonsense mutation of c.910 C $>\mathrm{T}$ in the FECH gene, resulting in p.Arg304Ter, was identified in the proband as well as her symptomatic mother, aunt, and asymptomatic male cousin. The proband and her living family members, except the asymptomatic male cousin, carried the alleles IVS 3-48C and IVS 1-23T on the $F E C H$ gene. The mutation of c.910 C $>\mathrm{T}$ in the $\mathrm{FECH}$ gene presented its heterozygous autosomal dominant inherent clinical manifestations, only in the presence of the heterozygous alleles IVS 3-48C and IVS 1-23T. The frequencies of the alleles IVS 3-48C and IVS 1-23T were $30.8 \%$ and $27.9 \%$ in a northeast Chinese Han population, respectively.

Conclusions: A new nonsense mutation of c.910 C $>$ T was identified in the FECH gene, which expressed EPP with severe liver dysfunction when it was co-inherited with the heterozygous alleles IVS 3-48C and IVS 1-23T, in a Chinese family.
\end{abstract}

Keywords: Nonsense Mutation, FECH, Erythropoietic Protoporphyria, Chinese

\section{Background}

Erythropoietic protoporphyria (EPP) is a relatively rare inherited disorder that is characterized by photosensitivity of skin exposed to sunlight. It is caused by partial deficiency of ferrochelatase $(\mathrm{FECH})$, which is the terminal enzyme of heme synthesis, leading to accumulation of free protoporphyrin IX in erythrocytes, other tissues (skin and liver), and biological fluids (bile and feces). The most common clinical manifestation of EPP is cutaneous photosensitivity in sun-exposed skin, including edema, erythema, itching, and burning (1-4). Scars form on the face and skin, particularly over the joints on the backs of the hands, become thick and waxy, and in rare cases, palmar keratoderma can occur in chronic patients (5-7). In addition to skin problems, $10 \%$ to $20 \%$ of EPP patients suffer from liver dysfunction. Moreover, protoporphyrin can form gallstones, resulting in an increased risk of cholelithiasis (1). Approximately $2 \%$ of patients with EPP develop fa- tal liver failure, and some patients need to be treated with liver transplantation (5, 8-13).

The mode of inheritance of EPP is complex. Among 190 mutations identified in the $F E C H$ gene in patients with EPP throughout the world (14), most are autosomal dominant with a low penetrance. Fewer than $10 \%$ of mutation carriers develop overt clinical symptoms (9). The activity of FECH is only $10 \%$ to $30 \%$ of the normal value in symptomatic EPP patients, and approximately $50 \%$ of the normal value in asymptomatic carriers (15). The phenotypic expression of EPP is generally the result of the coinheritance of a low-expressed wild-type allele and a mutant allele (16-18). The mechanism responsible for the low expression of the wild-type allele of FECH is the single nucleotide polymorphism IVS $3-48 \mathrm{~T} / \mathrm{C}(2,19)$. The single nucleotide polymorphism IVS 3-48 $\mathrm{T}>\mathrm{C}$ in the $\mathrm{FECH}$ gene modulates the use of a constitutive aberrant acceptor splice site, which is located $63 \mathrm{bp}$ upstream of the nor- 
mal one (17). The aberrantly spliced mRNA is degraded by a nonsense-mediated decay mechanism, leading to a decreased steady-state level of mRNA and additional FECH enzyme deficiency, necessary for EPP phenotypic expression. In western countries and Japan, ferrochelatase IVS 3$48 \mathrm{~T} / \mathrm{C}$ accounts for $85 \%$ to $90 \%$ of cases of EPP (2). The frequency of the low-expression allele, IVS3-48C, varies widely in different ethnic groups (19-21). The allele IVS 3-48C is distributed in an east-west gradient in China: from $41.35 \%$ in Shanghai, 28.9\% in Beijing, 28\% in Hong Kong, to putatively less than 1\% in Xi'an (22-24). Carriers of null-allele mutations in the FECH gene, which lead to the formation of a shorter mRNA and a truncated protein, are more likely to develop liver disease than carriers of missense mutations $(25,26)$.

Furthermore, EPP cases have been reported in Europe, United States, and Japan (27-31). However, only 16 EPP patients with detailed genetic information have been reported in a Chinese population (14, 22-24, 32-37). In the present study, one new mutation was identified in the $F E C H$ gene to cause EPP in a Chinese family, and the frequencies of the IVS 3-48C and IVS 1-23T polymorphisms were further assessed in a northeast Chinese Han population.

\section{Methods}

\subsection{Subjects}

This study was approved by the Ethics Committee of the First Hospital of Jilin University, Jilin, China. Each procedure in this study was performed after written consents were provided by the participants.

A total of 60 individuals were investigated in this study, including a family with EPP and 52 healthy individuals from a northeast Chinese Han population. In the family with EPP, except for the proband's grandfather, grandmother, and uncle, who had died, eight individuals, including the proband, her father, her mother, her aunt, her aunt's daughter and son, her uncle's wife, and her uncle's daughter, were tested.

\subsection{Genetic Analyses}

Phenotypic analyses were performed through clinical examination and laboratory testing for the living individuals; for individuals, who had died, their medical history was tracked. For genotyping, peripheral blood samples (approximately $5 \mathrm{~mL}$ ) were taken from the proband, the proband's family members, and healthy participants, using ethylene diamine tetraacetic acid-coated tubes, and sent to BGI Diagnosis Co., Shenzhen, Guangdong province,
China (certified with ISO 15189), for next-generation sequencing. Genomic DNA was isolated from peripheral blood samples, using a QIAamp DNA Blood Midi Kit (Qiagen, Hilden, Germany), then sheared by Covaris LE220 (Woburn, MA, USA) to generate a paired-end library (200 to $250 \mathrm{bp}$ ). The library was enriched by array hybridization, followed by elution and post-capture amplification. The products were subjected to analysis by an Agilent 2100 Bioanalyzer (Agilent, CA, USA) and ABI StepOne (Thermo Fisher Scientific, Waltham, MA, USA) to estimate the magnitude of enrichment. After quality control, captured library sequencing was carried out on Illumina HiSeq2500 Analyzers (Illumina, San Diego, CA, USA) for 90 cycles per read to generate paired-end reads. Image analysis, error estimation, and base calling were carried out using the Illumina Pipeline software (version 1.3.4; Illumina, San Diego, CA, USA) to generate raw data. Previously published filtering criteria were used to generate "clean reads" for further analysis (38).

The "clean reads" (with a length of $90 \mathrm{bp}$ ), derived from targeted sequencing and filtering, were then aligned to the human genome reference (hg19), using the Burrows Wheeler Aligner Multi-Vision software package (39). The SOAPsnp software (40) and Samtools (41) were used to detect single-nucleotide variants and insertion/deletions. The single-nucleotide variants and insertions/deletions were filtered and estimated through multiple databases, including NCBI dbSNP, HapMap, 1000 human genome dataset (42), and a database of 100 Chinese healthy adults. The Human Gene Mutation Database (43) was used to screen mutations reported in published studies. To validate the mutation, the FECH region, harboring the mutation, was screened using the Sanger method. The ALAS2, CPOX, HMBS, UROS, ALAD, PPOX, and UROD genes of the proband were also sequenced.

\section{Results}

\subsection{Characteristics of the Patients and Family Members}

The proband was a 16-year-old Han female, living in Jilin province, who was admitted to the First Hospital of Jilin University in 2017. Since her childhood, when she was exposed to sunlight, painful erythema and edema would immediately present on the palmar and dorsal aspects of her hands. The painful photosensitivity became severe during the summer and autumn. The skin over the joints on the dorsal aspects of her hands had become thick and waxy for several years. She took diphenhydramine as a treatment. One month prior to admission, she complained of jaundice, abdominal distension, severe abdominal pain, 
constipation, nausea, vomiting, neuralgia of all four limbs, and headache. Her family members, including her grandmother, mother, aunt, and uncle also had painful photosensitivity, and lived in Jilin Province. Her grandmother had died due to other reasons at the age of 72 years old, and her uncle had died from liver failure for an unknown reason at the age of 31 years old (Table 1 ).

Physical examination revealed marked jaundice and thickening of the skin over the joints on the backs of her hands. Her liver function test results (Table 2) showed that she had high levels of aspartate transaminase (AST), alanine aminotransferase (ALT), r-glutamyl-transpeptidase (r-GGT), alkaline phosphatase (ALP), and total bilirubin (TBIL). Routine blood tests showed normocytic anemia and an elevated reticulocyte percentage (Table 2). Her antinuclear antibody test and extractable nuclear antigen levels had not increased. Her blood tests for hepatitis A, B, C, and $\mathrm{E}$ viruses were negative, and her blood test for ceruloplasmin was normal. Urine porphyrins were normal. Free protoporphyrin in her erythrocytes was elevated (Table 2). Therefore, a diagnosis of EPP was made. Genetic testing was performed to confirm the diagnosis. She died due to liver failure one month after admission.

The proband's father, mother, aunt, aunt's daughter and son, uncle's wife, and uncle's daughter showed normal routine blood test results as well as liver and renal function.

\subsection{Genotyping}

Genetic screening showed that there were no variations or deletions in the sequences of ALAS2, CPOX, HMBS, UROS, ALAD, PPOX, and UROD of the proband. A heterozygous nucleotide change (c.910 C > T) and two heterozygous nucleotide polymorphism variations (IVS 1-23 C $>$ T and IVS 3-48 $\mathrm{T}>\mathrm{C}$ ) were detected in the FECH gene of the proband, her mother, and her aunt. The heterozygous nucleotide change (c.910 C>T) in the $F E C H$ gene was also detected in her aunt's son (Figures 1 and 2), who was asymptomatic. No nucleotide polymorphism variations (IVS 1-23 C $>$ T and IVS 3-48 T $>C$ ) were detected in the FECH gene of the proband's male cousin (Figures 1 and 2). The c.910 C>T mutation resulting in p.Arg304Ter is a null mutation (Table 1).

\subsection{Allele Frequency of the IVS 1-23 C/T and IVS 3-48 T/C Polymor- phisms}

The allele frequencies of the IVS 1-23 C/T and IVS 3-48 T/C polymorphisms in the northeast Chinese Han population were assessed by genotyping 52 healthy individuals without porphyria, liver, or skin disease. There were 25 females and 27 males; the average age was $42 \pm 9.9$ years old. They were all of Han ethnicity, living in Jilin province (Table 3). It was found that for allele IVS 1-23, 28 individuals had the $\mathrm{C} / \mathrm{C}$ genotype, 19 had the $\mathrm{C} / \mathrm{T}$ genotype, and five had the $\mathrm{T} / \mathrm{T}$ genotype, resulting in an IVS 1-23T allele frequency of $27.9 \%$ in the northeast Chinese Han population. It was also found that for IVS 3-48, 26 individuals had the T/T genotype, 20 had the $\mathrm{C} / \mathrm{T}$ genotype, and six had the $\mathrm{C} / \mathrm{C}$ genotype, resulting in an IVS 3-48C allele frequency of $30.8 \%$ in the northeast Chinese Han population (Table 4 ).

\section{Discussion}

In the present study, the proband presented clinical manifestations of photosensitivity, thick and waxy skin, and severe liver dysfunction, which are typical symptoms of EPP (1-7) accompanied with liver dysfunction (5, 813). Different degrees of severity of liver disease, include cholelithiasis, mild increased levels of aminotransferase, jaundice, and progressive end-stage liver disease. Furthermore, FECH deficiency causes accumulation of protoporphyrin in hepatocytes and bile canaliculi, leading to oxidative stress, cell damage, cytolysis, cholestasis, and further protoporphyrin retention $(1,44)$.

The presence of the same symptoms in her grandmother, mother, aunt, and uncle indicated that the proband might have had a genetic disease, which was further confirmed by the presence of the mutation of c.910 $\mathrm{C}>\mathrm{T}$ in the $\mathrm{FECH}$ gene of the proband, her mother, her aunt, and a male cousin.

The mutation of c.910 $\mathrm{C}>\mathrm{T}$ in the $\mathrm{FECH}$ gene found in this Chinese family is not among the 190 mutations identified in the FECH gene of patients with EPP throughout the world, indicating that this mutation has not been identified previously (43). The mutation corresponds to a $\mathrm{C}>\mathrm{T}$ substitution, resulting in the exchange of an arginine codon to a premature stop codon at codon 304, and leading to loss of a domain containing one section of the active-site pocket, six $\alpha$-helices ( $\alpha 12$ - $\alpha 17)$, two $\beta$-sheets ( $\beta 7$ $\beta 8)$, and part of the binding motif for the $(2 \mathrm{Fe}-2 \mathrm{~S})$ cluster in the FECH protein (45). The null mutation mediated clinical manifestations of severe liver dysfunction in the proband, which is consistent with the observations that carriers of null-allele mutations in the FECH gene are more likely to develop liver disease than are carriers of missense mutations $(25,26)$. Although it was difficult to determine whether the mutation was autosomal dominant or autosomal recessive, based on the phenotype and the pedigree, genetic screening indicated that the proband, her symptomatic mother, and her aunt were c.910 T mutation 
Xu Fetal.

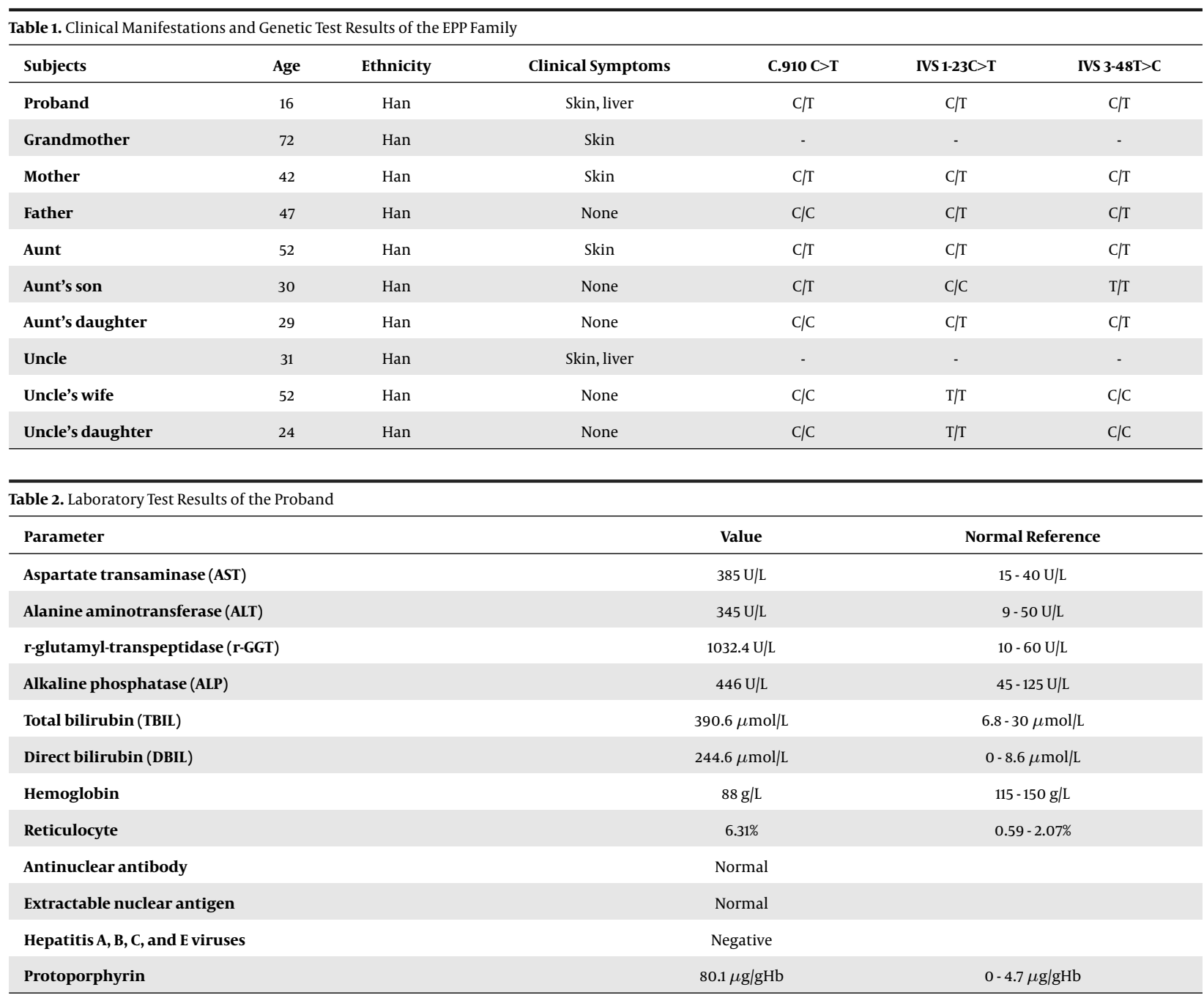

\begin{tabular}{lc}
\hline \multicolumn{2}{l}{ Table 3. Demographic Features of the Healthy Controls } \\
\hline & Controls \\
\hline Gender (female/male) & $25 / 27$ \\
Age $(\mathbf{y})$ & $42 \pm 9.9$ \\
Ethnicity & Han \\
Residential location & Jilin province in northeast China \\
\hline
\end{tabular}

heterozygous. The clinical manifestations were only expressed in the proband, her mother, and her aunt, who had a heterozygous c.910 T mutation, a heterozygous IVS 1-23 C $>$ T mutation, and a heterozygous IVS 3-48 T $>$ C mutation; while they were not expressed in the proband's male cousin, who had a heterozygous c.910 T mutation in the absence of a heterozygous IVS 1-23 C $>$ T or IVS 3-48 T $>$ C mutation, indicating that the phenotypic expression of the c.910
T mutation needs the co-existence of the c.910 T mutation with the heterozygous IVS 1-23 C $>$ T mutation or the IVS 3-48 $\mathrm{T}>\mathrm{C}$ mutation (14, 22-24, 32-37). Thus, the findings support the observation that the phenotypic expression of EPP results from the coinheritance of a low-expressed wild-type allele and a mutant allele $(16,17)$. Although the proband, her mother, and her aunt had the same genotype, only the proband had severe liver disease, suggesting that there might be other risk factors involved in the pathogenesis of EPP, such as epigenetic changes (31). Future studies are required for further clarification.

The observed IVS 3-48C allele frequency was $30.8 \%$ in the northeast Chinese Han population, which supports that there is an east-west distribution gradient of the IVS 3-48C allele in China (22-24). The IVS 1-23T allele frequency was found to be $27.9 \%$ in the northeast Chinese Han population, which is higher than that found in France (16). 


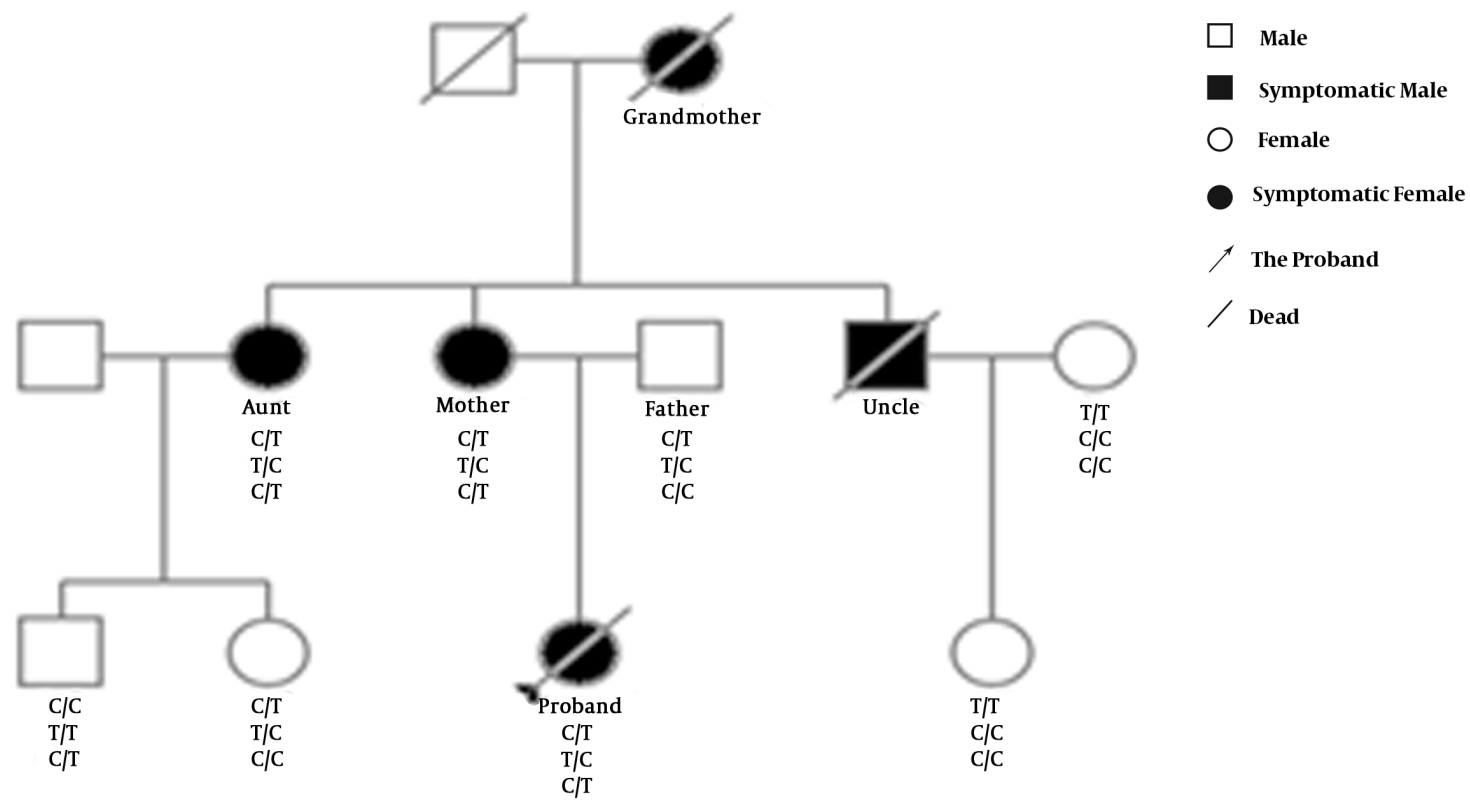

Figure 1. Pedigree of the Chinese family with erythropoietic protoporphyria analyzed in this study.

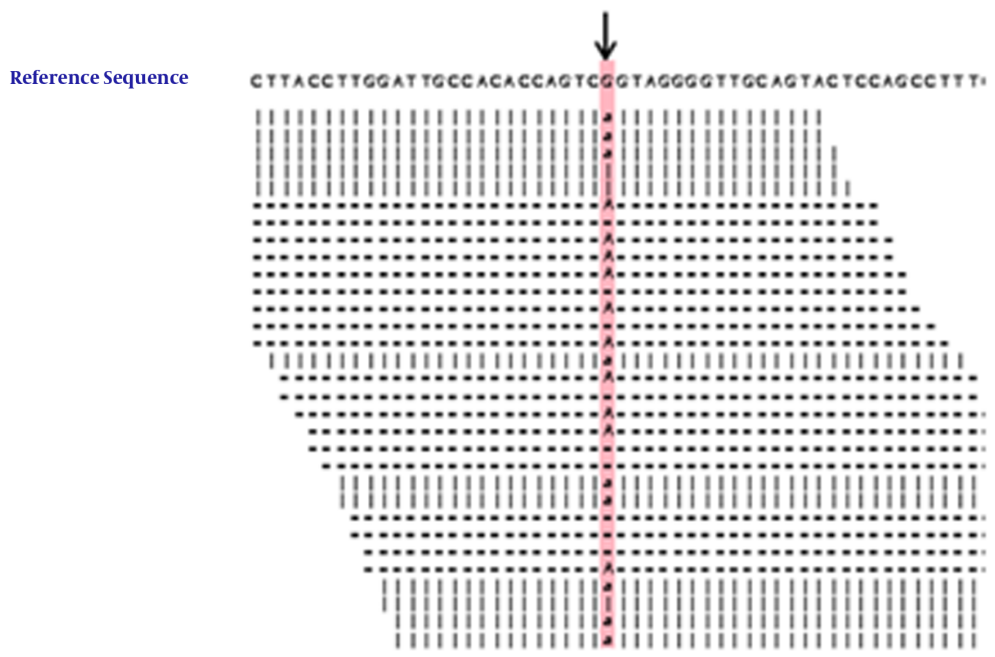

Figure 2. $\mathrm{C}>\mathrm{T}$ transition at $F E C H$ c.910.$\downarrow$, shows the $\mathrm{C}>\mathrm{T}$ mutation at $F E C H$ c.910, which caused the change of the arginine codon to a premature stop codon. The sequence shown in the figure is of the negative strand.

The relatively high frequencies of the IVS 3-48C allele and the IVS 1-23T allele in the northeast Chinese Han population implicate that it is not rare for mutations in the $F E C H$ gene to come together with alleles of IVS 3-48C and IVS 1$23 \mathrm{~T}$ through the reproductive recombination process, as observed in the Chinese family in the present study. 


\begin{tabular}{|c|c|c|c|c|c|}
\hline & \multicolumn{3}{|c|}{ No. of Subjects with Genotype } & \multicolumn{2}{|c|}{ Allelic Frequency } \\
\hline & $\mathrm{C} / \mathrm{C}$ & $\mathrm{C} / \mathrm{T}$ & $\mathbf{T} / \mathbf{T}$ & $\mathbf{T}$ & C \\
\hline IVS 1-23 & 28 & 19 & 5 & 0.279 & 0.921 \\
\hline IVS 3-48 & 6 & 20 & 26 & 0.692 & 0.308 \\
\hline
\end{tabular}

One limitations of the present study was its small sample size. Since EPP is a rare inherited disorder, only a very small number of patients and control subjects were included in this study. However, the definite pedigree relationship among the patients and other members of the same family helped elucidate the inheritance pattern of the disease.

In conclusion, a new nonsense mutation of c.910 C $>\mathrm{T}$ was identified in the $F E C H$ gene, which expressed EPP with severe liver dysfunction when a heterozygous allele of the mutation was co-inherited with heterozygous IVS 3-48C and IVS 1-23T, in a Chinese family.

\section{Acknowledgments}

This work was supported by Jilin Natural Science Foundation of China (20130101155JC).

\section{Footnotes}

Conflicts of Interests: The authors declare that there were no conflicts of interest.

Funding/Support: This work was supported by Jilin Natural Science Foundation of China (20130101155JC).

\section{References}

1. Puy H, Gouya L, Deybach JC. Porphyrias. Lancet. 2010;375(9718):924-37. doi: 10.1016/S0140-6736(09)61925-5. [PubMed: 20226990].

2. Bissell DM, Anderson KE, Bonkovsky HL. Porphyria. N Engl J Med. 2017;377(9):862-72. doi:10.1056/NEJMra1608634. [PubMed: 28854095].

3. Lecha M, Puy H, Deybach JC. Erythropoietic protoporphyria. Orphanet J Rare Dis. 2009;4:19. doi: 10.1186/1750-1172-4-19. [PubMed: 19744342]. [PubMed Central: PMC2747912].

4. Karim Z, Lyoumi S, Nicolas G, Deybach JC, Gouya L, Puy H. Porphyrias: A 2015 update. Clin Res Hepatol Gastroenterol. 2015;39(4):412-25. doi: 10.1016/j.clinre.2015.05.009. [PubMed: 26142871].

5. Todd DJ. Erythropoietic protoporphyria. BrJDermatol.1994;131(6):75166. [PubMed: 7857832].

6. Holme SA, Whatley SD, Roberts AG, Anstey AV, Elder GH, Ead RD, et al. Seasonal palmar keratoderma in erythropoietic protoporphyria indicates autosomal recessive inheritance. J Invest Dermatol. 2009;129(3):599-605. doi: 10.1038/jid.2008.272. [PubMed: 18787536].

7. Schmidt H, Snitker G, Thomsen K, Lintrup J. Erythropoietic protoporphyria. A clinical study based on 29 cases in 14 families. Arch Dermatol. 1974;110(1):58-64. [PubMed: 4420906].
8. Doss MO, Frank M. Hepatobiliary implications and complications in protoporphyria, a 20-year study. Clin Biochem. 1989;22(3):223-9. [PubMed: 2736774].

9. Schneider-Yin X, Gouya L, Meier-Weinand A, Deybach JC, Minder EI. New insights into the pathogenesis of erythropoietic protoporphyria and their impact on patient care. Eur J Pediatr. 2000;159(10):719-25. [PubMed: 11039124].

10. Bloomer J, Bruzzone C, Zhu L, Scarlett Y, Magness S, Brenner D. Molecular defects in ferrochelatase in patients with protoporphyria requiring liver transplantation. J Clin Invest. 1998;102(1):107-14. doi: 10.1172/JCl1347. [PubMed: 9649563]. [PubMed Central: PMC509071].

11. Polson RJ, Lim CK, Rolles K, Calne RY, Williams R. The effect of liver transplantation in a 13-year-old boy with erythropoietic protoporphyria. Transplantation. 1988;46(3):386-9. [PubMed: 3047929].

12. Thunell S, Harper P, Brun A. Porphyrins, porphyrin metabolism and porphyrias. IV. Pathophysiology of erythyropoietic protoporphyria diagnosis, care and monitoring of the patient. Scand J Clin Lab Invest. 2000;60(7):581-604. [PubMed: 11202051].

13. Windon AL, Tondon R, Singh N, Abu-Gazala S, Porter DL, Russell JE, et al. Erythropoietic protoporphyria in an adult with sequential liver and hematopoietic stem cell transplantation: A case report. Am J Transplant. 2018;18(3):745-9. doi: 10.1111/ajt.14581. [PubMed: 29116687].

14. Long ZB, Wang YW, Yang C, Liu G, Du YL, Nie GJ, et al. Identification of FECH gene multiple variations in two Chinese patients with erythropoietic protoporphyria and a review. J Zhejiang Univ Sci B. 2016;17(10):813-20. doi: 10.1631/jzus.B1600085. [PubMed: 27704751]. [PubMed Central: PMC5064175].

15. Gouya L, Deybach JC, Lamoril J, Da Silva V, Beaumont C, Grandchamp $B$, et al. Modulation of the phenotype in dominant erythropoietic protoporphyria by a low expression of the normal ferrochelatase allele. Am J Hum Genet. 1996;58(2):292-9. [PubMed: 8571955]. [PubMed Central: PMC1914527].

16. Gouya L, Puy H, Lamoril J, Da Silva V, Grandchamp B, Nordmann $\mathrm{Y}$, et al. Inheritance in erythropoietic protoporphyria: A common wild-type ferrochelatase allelic variant with low expression accounts for clinical manifestation. Blood.1999;93(6):2105-10. [PubMed: 10068685].

17. Gouya L, Puy H, Robreau AM, Bourgeois M, Lamoril J, Da Silva V, et al. The penetrance of dominant erythropoietic protoporphyria is modulated by expression of wildtype FECH. Nat Genet. 2002;30(1):27-8. doi: 10.1038/ng809. [PubMed: 11753383].

18. Gouya L, Puy H, Robreau AM, Lyoumi S, Lamoril J, Da Silva V, et al. Modulation of penetrance by the wild-type allele in dominantly inherited erythropoietic protoporphyria and acute hepatic porphyrias. Hum Genet. 2004;114(3):256-62. doi: 10.1007/s00439-003-1059-5. [PubMed: 14669009].

19. Gouya L, Martin-Schmitt C, Robreau AM, Austerlitz F, Da Silva V, Brun $\mathrm{P}$, et al. Contribution of a common single-nucleotide polymorphism to the genetic predisposition for erythropoietic protoporphyria. Am J Hum Genet. 2006;78(1):2-14. doi: 10.1086/498620. [PubMed: 16385445]. [PubMed Central: PMC1380220]. 
20. Whatley SD, Mason NG, Khan M, Zamiri M, Badminton MN, Missaoui $\mathrm{WN}$, et al. Autosomal recessive erythropoietic protoporphyria in the United Kingdom: Prevalence and relationship to liver disease. J Med Genet. 2004;41(8). e105. doi: 10.1136/jmg.2003.016121. [PubMed: 15286165]. [PubMed Central: PMC1473220].

21. Cordiali Fei P, Macri A, Trento E, D'Agosto G, Griso D, Biolcati F, et al. Flow cytometric analysis of fluorocytes in patients with erythropoietic porphyria. Eur J Histochem. 1997;41 Suppl 2:9-10. [PubMed: 9859759].

22. Zhou SN, Xiao SX, Peng ZH, Li BX, Li XL, Liu Y, et al. A novel mutation of the $\mathrm{FECH}$ gene in a Chinese family with erythropoietic protoporphyria. J Dermatol Sci. 2007;48(2):145-7. doi: 10.1016/j.jdermsci.2007.07.004. [PubMed: 17723290].

23. Kong XF, Ye J, Gao DY, Gong QM, Zhang DH, Lu ZM, et al. Identification of a ferrochelatase mutation in a Chinese family with erythropoietic protoporphyria. J Hepatol. 2008;48(2):375-9. doi: 10.1016/j.jhep.2007.09.013. [PubMed: 18160121]

24. Lau KC, Lam CW, Fong B, Siu TS, Tam S. DNA-based diagnosis of erythropoietic protoporphyria in two families and the frequency of a low-expression FECH allele in a Chinese population. Clin Chim Acta. 2009;400(1-2):132-4. doi: 10.1016/j.cca.2008.09.031. [PubMed: 18976643].

25. Chen FP, Risheg H, Liu Y, Bloomer J. Ferrochelatase gene mutations in erythropoietic protoporphyria: Focus on liver disease. Cell Mol Bio (Noisy-le-grand). 2002;48(1):83-9. [PubMed: 11929052].

26. Cox TM. Erythropoietic protoporphyria. J Inherit Metab Dis. 1997;20(2):258-69. [PubMed: 9211198].

27. Henriksson M, Timonen K, Mustajoki P, Pihlaja H, Tenhunen R, Peltonen $\mathrm{L}$, et al. Four novel mutations in the ferrochelatase gene among erythropoietic protoporphyria patients. J Invest Dermatol. 1996;106(2):346-50. [PubMed: 8601739].

28. Rufenacht UB, Gouya L, Schneider-Yin X, Puy H, Schafer BW, Aquaron $\mathrm{R}$, et al. Systematic analysis of molecular defects in the ferrochelatase gene from patients with erythropoietic protoporphyria. Am J Hum Genet. 1998;62(6):1341-52. doi: 10.1086/301870. [PubMed: 9585598]. [PubMed Central: PMC1377149]

29. Wang X, Yang L, Kurtz L, Lichtin A, DeLeo VA, Bloomer J, et al Haplotype analysis of families with erythropoietic protoporphyria and novel mutations of the ferrochelatase gene. $J$ Invest Dermatol. 1999;113(1):87-92. doi: 10.1046/j.1523-1747.1999.00637.x. [PubMed: 10417624].

30. Saruwatari H, Ueki Y, Yotsumoto S, Shimada T, Fukumaru S, Kanekura $\mathrm{T}$, et al. Genetic analysis of the ferrochelatase gene in eight Japanese patients from seven families with erythropoietic protoporphyria J Dermatol. 2006;33(9):603-8. doi: 10.1111/j.1346-8138.2006.00140.x. [PubMed: 16958804]

31. Onaga Y, Ido A, Uto H, Hasuike S, Kusumoto K, Moriuchi A, et al. Hypermethylation of the wild-type ferrochelatase allele is closely associated with severe liver complication in a family with erythropoietic protoporphyria. Biochem Biophys Res Commun. 2004;321(4):851-8. doi 10.1016/j.bbrc.2004.06.178. [PubMed:15358105].

32. Zhang F, Lu L, Qian X, Pu LY, Li GQ, Wang XH. Liver transplantation for erythropoietic protoporphyria with hepatic failure: A case report. Transplant Proc. 2008;40(5):1774-6. doi: 10.1016/j.transproceed.2008.03.082. [PubMed:18589193]

33. Ma J, Xiao S, An J, Wang X, Xu Q, Dong Y, et al. A novel splicing mutation and haplotype analysis of the $\mathrm{FECH}$ gene in a Chinese family with erythropoietic protoporphyria. J Eur Acad Dermatol Venereol. 2010;24(6):726-9. doi: 10.1111/j.1468-3083.2009.03471.x. [PubMed: 19888946].

34. Xiaoqing LI, Jie SHI, Yamin LAI. protoporphyria with jaundice as the main manifestation: A clinical, pathological, and genetic analysis of 4 cases. J Clin Hepatol. 2017;33(7):1332-5. doi: 10.3969/j.issn.10015256.2017.07.026.

35. Ma JH, Xiao SX, An JG, Wang XP, Xu QQ, Dong YY, et al. [Mutation analysis of ferrochelatase gene in a pedigree with erythropoietic protoporphyria]. Chinese J Dermatol. 2010;43(2):85-7. Chinese.

36. Feng L. [A erythropoietic protoporphyria with the main manifestation of liver injury and abdominal pain]. Chinese JDigestion. 2017;2(37). Chinese.

37. Ma J. [The relationship between gene expression and phenotype in rythropoietic protoporphyria]. Chinese J Dermatol. 2013;7(46). Chinese.

38. Wei X, Ju X, Yi X, Zhu Q, Qu N, Liu T, et al. Identification of sequence variants in genetic disease-causing genes using targeted next-generation sequencing. PLoS One. 2011;6(12). e29500. doi: 10.1371/journal.pone.0029500. [PubMed: 22216297]. [PubMed Central: PMC3244462].

39. Li H, Durbin R. Fast and accurate short read alignment with Burrows-Wheeler transform. Bioinformatics. 2009;25(14):1754-60. doi: 10.1093/bioinformatics/btp324. [PubMed:19451168].[PubMed Central: PMC2705234].

40. Li R, Li Y, Fang X, Yang H, Wang J, Kristiansen K, et al. SNP detection for massively parallel whole-genome resequencing. Genome Res.2009;19(6):1124-32.doi:10.1101/gr.088013.108. [PubMed:19420381]. [PubMed Central: PMC2694485].

41. Li H, Handsaker B, Wysoker A, Fennell T, Ruan J, Homer N, et al. The Sequence Alignment/Map format and SAMtools. Bioinformatics. 2009;25(16):2078-9. doi:10.1093/bioinformatics/btp352. [PubMed: 19505943]. [PubMed Central: PMC2723002].

42. Auton A, Brooks LD, Durbin RM, Garrison EP, Kang HM; Genomes Project Consortium, et al. A global reference for human genetic variation. Nature. 2015;526(7571):68-74. doi:10.1038/nature15393. [PubMed: 26432245]. [PubMed Central: PMC4750478].

43. Stenson PD, Mort M, Ball EV, Evans K, Hayden M, Heywood S, et al. The human gene mutation database: Towards a comprehensive repository of inherited mutation data for medical research, genetic diagnosis and next-generation sequencing studies. Hum Genet. 2017;136(6):665-77. doi: 10.1007/s00439-017-1779-6. [PubMed: 28349240]. [PubMed Central: PMC5429360].

44. Casanova-Gonzalez MJ, Trapero-Marugan M, Jones EA, Moreno-Otero R. Liver disease and erythropoietic protoporphyria: A concise review. World J Gastroenterol. 2010;16(36):4526-31. [PubMed: 20857522]. [PubMed Central: PMC2945483].

45. Wu CK, Dailey HA, Rose JP, Burden A, Sellers VM, Wang BC. The 2.0 A structure of human ferrochelatase, the terminal enzyme of heme biosynthesis. Nat Struct Biol. 2001;8(2):156-60. doi: 10.1038/84152. [PubMed: 11175906]. 